\title{
Learning to Frame Complex Sustainability Challenges in Place: Explorations Into a Transdisciplinary "Challenge Lab" Curriculum
}

\author{
Gavin McCrory ${ }^{1 *}$, Johan Holmén ${ }^{1}$, John Holmberg ${ }^{1}$ and Tom Adawi ${ }^{2}$ \\ ${ }^{1}$ Department of Space, Earth and Environment, Division Physical Resource Theory, Chalmers University of Technology, \\ Gothenburg, Sweden, ${ }^{2}$ Department of Communication and Learning in Science, Division of Engineering Education Research, \\ Chalmers University of Technology, Gothenburg, Sweden
}

\section{OPEN ACCESS}

Edited by: Subarna Sivapalan

University of Technology

Petronas, Malaysia

Reviewed by:

Dena Fam,

University of Technology

Sydney, Australia

Núria Bautista-Puig

University of Gävle, Sweden

*Correspondence:

Gavin McCrory

mccrory@chalmers.se

Specialty section

This article was submitted to

Sustainable Organizations,

a section of the journal

Frontiers in Sustainability

Received: 24 May 2021

Accepted: 08 July 2021

Published: 24 August 2021

Citation:

McCrory G, Holmén J, Holmberg J and Adawi T (2021) Learning to Frame

Complex Sustainability Challenges in

Place: Explorations Into a

Transdisciplinary "Challenge Lab"

Curriculum. Front. Sustain. 2:714193.

doi: 10.3389/frsus.2021.714193
Complex sustainability challenges may never be fully solved, rather requiring continuous, adaptive, and reflexive responses over time. Engagement of this nature departs from well-structured problems that entail expected solutions; here, focus shifts toward ill-structured or ill-defined issues characterized by wickedness. In the context of complex challenges, inadequate or absent framing has performative implications on action. By overlooking the value of framing, eventual responses may not only fall short; they may even displace, prolong, or exacerbate situations by further entrenching unsustainability. In educational settings, we know little about how curriculum designs support challenge framing, and how students experience and learn framing processes. In this paper we explore a transdisciplinary "Challenge Lab" (C-Lab) curriculum from a perspective of challenge framing. When considering framing in higher education, we turn to the agenda in education for, as and with sustainable development to be problem-solving, solutions-seeking or challenge-driven. We introduce framing as a boundary object for transformative praxis, where sustainability is held to be complex and contextual. This study is qualitative and case-based, designed to illuminate processes of and experiences into sustainability challenge framing in a transdisciplinary learning setting. Methodologically, we draw from student reflective diaries that span the duration of a curriculum design. We structure our results with the support of three consecutive lenses for understanding "curriculum": intended, enacted, and experienced curriculum. First, we present and describe a C-Lab approach at the level of ambition and design. Here it is positioned as a student-centered space, process, and institutional configuration, working with framing and re-framing complex sustainability challenges in context. Second, we present a particular C-Lab curriculum design that unfolded in 2020. Third, we illustrate the lived experiences and practical realities of participating in C-Lab as students and as teachers. We reflect upon dilemmas that accompany challenge framing in C-Lab and discuss the methodological implications of this study. Finally, we point toward fruitful research avenues that may extend understandings of challenge framing in higher education.

Keywords: higher education, transformative learning, challenge framing, education for sustainable development, curriculum theory, sustainability transitions 


\section{INTRODUCTION}

\begin{abstract}
"The idea of problem-solving, so central to the idea of mode 2knowledge, is problematic because it implies that-with sufficient imagination, daring and creativity - a solution can be designed. But issues of sustainability opens up for a world in which solutions cannot be designed, in the sense that a problem has been entirely satisfactorily met; there are always repercussions, unintended consequences and loose ends" (Barnett, 2004, p. 251).
\end{abstract}

Complex sustainability challenges may never be fully solved, rather requiring continuous, adaptive, and reflexive engagement over time. Engagement of this nature departs from wellstructured problems that entail expected solutions; here, focus shifts toward ill-structured or ill-defined issues characterized by wickedness (Rittel and Webber, 1973). Prominent approaches to grapple with wickedness include transdisciplinary (TD) knowledge production, where actors across sectors, disciplines and perspectives mobilize around a shared challenge or question of concern in context (Lang et al., 2012).

The ways in which sustainability challenges become framed are influential in how they are acted upon. Framing is "the process by which people develop a particular conceptualization of an issue or reorient their thinking about an issue" (Chong and Druckman, 2007, p. 103). It is understood as an unfolding process of meaning-making where the categorization of a complex reality occurs (Benford and Snow, 2000). Myopic attention to challenge framing has performative implications on action. By overlooking the value of framing, eventual responses may not only fall short; they may even displace, prolong, or exacerbate situations by further entrenching unsustainability ${ }^{1}$ (Ross and Mitchell, 2018). In systems thinking circles, questions of boundaries and values are central in framing, where one both searches for underlying, root causes and conceives of ethical action (Midgley, 2000; Meadows, 2008; Jackson, 2010). Further, challenge framing appears in processes of learning and transformation. Mezirow (1997) characterizes transformative learning as "changes in frames of reference," (Bateson, 1972) as "changes in world view" and Meadows (1997) deepest leverage points operate on a level of mental-model, worldview and paradigm.

In this paper we explore a TD "Challenge Lab" (C-Lab) approach from the perspective of challenge framing. C-Lab seeks to create space for, and support students in, leading processes around complex sustainability challenges with societal actors. It strives to integrate education, research, and outreach as a mode of transformative Education for Sustainable Development (ESD). In ESD learning, students are expected to both unravel the complexities of sustainability and develop agency in acting (UNESCO, 2014). Here, conventional notions of the classroom are disrupted, in favor of "real" and situated societal settings

\footnotetext{
${ }^{1}$ Complex challenges do not adhere neatly to disciplinary knowledge; they do not invite singular definitions of a problem and rational solutions. Bardwell (1991) highlights this challenge by stating that problem-solving agendas are susceptible to: (1) solving the wrong problem, (2) stating the problem so it cannot be solved, (3) solving a solution, (4) stating problems too generally and (5) trying to get agreement on the solution before there is agreement on the problem.
}

where students shift from consumers to producers of knowledge (Moore, 2005; Waters, 2017; Bornemann and Christen, 2020). These spaces bring a diverse and inclusive set of pedagogies that mobilize hand, head, and heart (Sipos et al., 2008), recognizing the limits to transmission approaches to learning.

To date, we know little about how curriculum designs support challenge framing, and how students experience and learn framing processes. This is partly due to prevailing tendencies in sustainability-oriented education. Here, students are invited to solve pre-established issues, but not frame them (Tilbury, 2016; Pohl et al., 2020). Initiatives with grounded procedures to challenge framing are still emerging but are less researched. Currently, they come from design contexts (Beckman and Barry, 2012; Cf. Irwin, 2015) focusing on e.g., framing design interventions across multiple scales on pre-defined topical challenges for fostering social learning (Lopes et al., 2012; Fam et al., 2020). We have a general interest in how framingoriented curricula work in practice and come into meaning for those involved. In addition, we have a curiosity in how higher education institutions can provide conditions conducive to openended curriculum with transformative sustainability ambitions. We dedicate the rest of this paper to explore challenge framing from a perspective of the C-Lab approach and a particular curriculum. In contrast to a procedural step in a problem-solving process (Will and Rydén, 2015), our interest lies with framing sustainability challenges as reflexively entangled within various commitments to action.

In challenge framing in ESD, we introduce framing as a boundary object for praxis, where sustainability is held to be complex and contextual. In challenge lab, we draw upon curriculum theory to position C-Lab as a student-centered space, process, and institutional configuration, working with framing and re-framing complex sustainability challenges in context. First, in 3.1, we present and describe a C-Lab approach at the level of ambition and design, with a specific focus on challenge framing. Second, in the enacted C-lab curriculum, we direct attention toward a particular C-Lab curriculum design that unfolded in 2020. Third, in the experienced C-lab curriculum we then attempt to illustrate the lived experiences and practical realities of participating in C-Lab as students and as teachers/practitioners.

\section{CHALLENGE FRAMING IN ESD}

To guide our work, we understand framing as a boundary object for exploring Challenge Lab (C-Lab). In inter- and transdisciplinary settings, boundary objects offer promise in transgressing divisions to knowledge (Star and Griesemer, 1989; Brand and Jax, 2007). They achieve this by creating a shared object as a basis for collaboration and dialogue. Such objects are well-suited to educational arrangements whose focus lies with wider issues, challenges, or messes, as matters for the integration of knowledge and practice (Robinson, 2008; Busch et al., 2019). In our understanding of framing, we draw from educational and learning sciences, systems thinking, sustainability science, ESD, political sciences and TD. We maintain a broad orientation 
with framing to allow for an emergent approach to our work. In educational settings at the level of pedagogy, framing can be understood as a: (1) conceptual or theoretical point of entry, (2) social phenomenon, mediated through language and relations, (3) continuous matter of praxis that unfolds in context.

In higher education, we turn toward the agenda of education for, as and with sustainable development to be problem-solving, solutions-seeking or challenge-driven (Thomas, 2009; Tilbury, 2012). This agenda advocates for both science and education to be forces for good (Chatterton, 2000; Trencher et al., 2014; Moser, 2021). In many settings, problems are defined as simple objects at the beginning of an educational or research process (Eden and Ackermann, 2013; Archibald, 2020). Problems are often given "as-is" or shaped according to a specific understanding of an issue at hand, from the view of the teacher. In linear approaches to problem solving, a stepwise movement from problem to solution takes place at the problem formulation, definition, or structuring stage (Jerneck and Olsson, 2011; Eden and Ackermann, 2013; Will and Rydén, 2015). Implicit in such endeavors through the labeling of "problems" is the assumption that there is a degree of resolution or solvability possible.

In moving away from positivist understandings of frames as neutral, objective, static and ultimate, we recognize that mainstream approaches to education are ill-equipped to collectively engage with transformations in place. In environments that are both problem-based and solutionoriented, framing is of utmost importance (Svihla and Reeve, 2016; Ness, 2020). Frames and framing processes are essential in approaching wicked challenges, referred to as messes (Ackoff, 1973), problematic situations (Checkland and Poulter, 2010), matters of concern (Latour, 2004), or in-between issues (Vilsmaier and Lang, 2015; Ison, 2017). In this paper, we draw from and extend the notion of problem-framing by focusing on complex challenges to be engaged with, rather than problems to be solved. Our understanding of "challenge" aligns more with a view of challenges as situated, whose structure and meaning unfolds through collaborative engagement.

In complex issues linked to unsustainability, linear approaches to framing largely fall short (Boulton et al., 2015). Rather than problems and solutions to be singular and fixed-as has been the case in (often referred to as) hard-sciences and aspects of engineering that deal with problems of a complicated-mechanical nature-it is possible to see issues of complex-social nature (Cf. Andersson et al., 2014) as subject to processes of framing. Given their ill-structured and wicked nature, one must approach real-world problems as subject to continuous change, becoming continuously framed or in need of continuous framing (Rittel and Webber, 1973). In higher education, authentic contexts and challenges of a wicked nature are argued to be conducive to transformative learning processes (Mezirow, 1997) and agency expression (LotzSisitka et al., 2015), providing support for deep reflection on the assumptions behind certain environments, courses and challenges.

A broad conception of framing accommodates a sociocultural perspective that recognizes the socio-relational elements of open-ended learning processes. We view framing as interactional, where diverse representations and understandings of a challenge are subject to expansion, de-framing, and reframing. As such, "frames are neither structural determinations of the meaning of situations, nor are they individual schemes of cognition or stabilized routines" (Lorino et al., 2017, p. 35). Challenge framing is not predictive, but rather performative; throughout an unfolding process, framing processes shape the relevance of certain issues, directing attention, influencing value and goal-setting and structuring an understanding of progress, success and failure (Schön, 2008; Ison et al., 2015; Lorino et al., 2017). These dimensions are not limited to student experiences in organizing around a complex issue, but extend toward the interplay between students, teachers and others involved in the learning situation.

\section{CHALLENGE LAB}

In the following subsections, we present the Challenge Lab (C-Lab) approach to challenge framing from three different dimensions. Firstly, we motivate C-Lab at the level of intention. Here, we highlight central tenets that underpin the C-Lab approach. Secondly, we outline C-Lab as curriculum, structured around these tenets in a higher education setting. Thirdly, we integrate student experiences and facilitator reflections from C-Lab. Our exploration into a C-Lab curriculum is qualitative and case-based (Lund, 2014), designed to illuminate processes and experiences of sustainability challenge framing. We draw from continuous student reflective diaries that span main components of the curriculum studied. Reflective diaries provide a continuous and introspective source of qualitative data (Moon, 2001; van der Horst and Staddon, 2018; Wallin and Adawi, 2018), enabling us to explore student experience. Analytically, we iteratively move between data and theory to depict student experiences in framing and enabling and constraining factors related to its wider situatedness in process and context. This inductive approach to data analysis takes the form of a thematic analysis, organized around the broad question "how do students experience challenge-driven educational curriculum?" (Saldaña, 2021). In inductive approaches, the concreteness of empirical instances provides the basis for concept-theory development (Yin, 2011). Open-ended coding enabled the development of broad categories from the raw data. This data was structured to analytically present student experiences, transformative incidents, and ongoing dilemmas. This form of thematic analysis leads to the condensation of meaning from the lived experiences of students and teachers as co-learners in C-lab.

To structure our exploration, we borrow insights from curriculum theory. We draw on a distinction between three ways of understanding "curriculum" (Billett, 2006). Intended curriculum refers to what teachers want their students to learn and how, reflected in the learning objectives and the overall design of a curriculum. Enacted curriculum refers to how teaching and learning activities designed to help students attain the learning objectives are (actually) enacted with and by students. Experienced curriculum refers to students' learning 
experiences and outcomes. Hume and Coll (2010) explain the educational significance of this three-pronged analytical frame:

\begin{abstract}
"Research findings that can shed light on the match between curriculum intent and classroom reality in [...] dynamic and complex educational environments [...] are important when evaluating how effectively curriculum goals are actually being met and help inform decisions about what steps may be needed to improve outcomes for students" (p. 45).
\end{abstract}

C-Lab emerged through strategic efforts of Chalmers University of Technology in Gothenburg, Sweden to enhance its institutional capacity and relevance for complex sustainability challenges and societal transformations (Holmberg, 2014). It sought to integrate three constitutive elements of the "knowledge triangle": research, education, and outreach/innovation. Underpinned by a capability to be challenging yet unthreatening in real-world contexts, C-Lab students were positioned uniquely when openly questioning stakeholders around a complex issue and learning about how systems do and should work (Holmberg, 2014; Larsson and Holmberg, 2018). Disciplinary backgrounds are de-emphasized in this environment, done with the recognition that transdisciplinarity transgresses disciplines as deterministic categories, where challenges require diverse forms of knowledge and experience (Lotz-Sisitka et al., 2015; Ross and Mitchell, 2018).

C-Lab seeks to operate on four levels toward: (1) system innovation, with multiple stakeholders on complex sustainability challenges, (2) a whole-of-institution approach to integrate education, research, and innovation/outreach, (3) crosseducational programme and department engagement, and (4) engaging students as leaders for sustainability transitions through education. As a strategic effort oriented around institutional capacities, regional stakeholder relationships and navigating sustainability transformations, C-Lab was provided financial support from Vinnova, the Swedish Innovation Agency to pursue educational ambitions. Although it was not initiated from within the formal education structures at its hosting University, it eventually became an institutionalized educational opportunity. Many participating students study engineering at the master's level. They often hold a prior motivation to contribute to sustainability transformations. Gender distribution tends to be equal across male and female; roughly half of the students have a Swedish background. Sub-disciplines are mixed, ranging from civil, mechanical and chemical engineering, to engineering design, and industrial engineering \& management.

Parallel and prior to the C-Lab curriculum lies a history of TD research and practice for sustainability transitions within educational as well as informal learning settings. We could thus conceive of it less as the C-Lab approach and rather $a$ C-Lab approach.

\section{The Intended C-Lab Curriculum}

Educationally, C-Lab assumes that practical engagement with complex sustainability challenges, informed by theory and underpinned by critical reflection, is a fruitful basis for students to learn about transformations in place. The space for learning becomes the authentic context where sustainability challenges originate, alongside actors with knowledge and influence over how systems develop. Challenge Lab intends to focus on complex "in-between" challenges. Here, no single actor has full knowledge or mandate to act, necessitating a transdisciplinary, co-creative approach.

As a leadership approach, C-Lab aims to foster leadership capabilities at three levels: (1) leading oneself, (2) leading together with others, and (3) leading for humanity. It seeks to pursue a student-centered pedagogy to foster high degrees of autonomy, engagement and student ownership of the learning space and associated processes. Here, it is important to not only acknowledge the outside-in dimensions of learning and change as engaging with systems "out there"; but also, the insideout dimensions of learning and change in building upon what students bring and become by participating in the lab.

Learning objectives of C-Lab emphasize the inner leadership capabilities of students in sustainability transitions. These objectives link to prevalent competence frameworks for sustainability (Barth et al., 2007; Wiek et al., 2011). It prioritizes an approach where students can generate their own "definition" of what leadership for sustainability transition means for them. Based on these considerations, C-Lab assesses students less on "boxed" and pre-defined learning objectives and outcomes. Rather, focus is placed on students' internal, reasoned and often emergent processes of becoming and quality of their reflection. We believe that a combination of outside-in and inside-out learning and change opens avenues for more transformative learning experiences for students and others involved, as a way to transgress notions of "knowledge to action". Conversely, it highlights the often-complex interplays between analysis and agency involved in real processes of change ( $\mathrm{O}^{\prime} \mathrm{Brien}$, 2013; Lotz-Sisitka et al., 2017; West et al., 2019). Here, we may distinguish between three qualitatively different levels of learning building on the work by Bateson (1972), as (1) "doing things better," (2) "doing better things," and (3) "seeing the world anew" (Winter et al., 2015). When interested in processes of transformation, we hold primary interest in learning at second and third levels, where students themselves experience what they do as meaningful.

In working toward such objectives, we seek to frame C-Lab in a safe space of openness, trust and care, a neutral arena, for people across hierarchies and organizations to meet. We broadly structure the C-Lab curriculum on a backcasting approach that forms a basis for its pedagogy. In backcasting, there is an explicit ambition to transgress conventional logics of problem solving, with an approach grounded in purpose, values, and intents. In addition to its practical and procedural forms, we frame a process that supports in (a) thinking beyond what currently is, into what is truly important and desired, (b) thinking broad, involving multiple dimensions and aspects of sustainability and perspectives on systems, (c) thinking behind/below by moving from symptoms and events to its (underlying) causes and reasons, (d) thinking forward by moving across description/analysis and prescription/action, and (e) thinking together in TD collaboration. A series of frameworks, methods and tools are used to help in framing and addressing 
complex sustainabilitys challenge in context. Tools include, but are not limited to, sustainability principles, systems- and design thinking, dialogue techniques and purposeful experimentation. We also seek to foster capability on a level above those into craft and quality, guided by awareness and critical reflection upon assumptions around how the world works, as well as the role of human agency in change processes.

\section{The Enacted C-Lab Curriculum}

The C-Lab curriculum ${ }^{2}$ consists of two master's level courses (à 7.5 ECTS) and a master thesis opportunity (30 ECTS). The first course is called "leadership for sustainability transitions" and hosts up to 45 students, followed by a second course "systems interventions for sustainability transitions" hosting up to 20 students (information on student backgrounds presented early in challenge lab). The leadership course consists of a mixed format of: (i) lectures where theories, frameworks, concepts, methods, and tools are introduced; (ii) case work where those are applied in practice, and (iii) reflection and knowledge integration from experience related to theory and practice. The latter course deepens the systemic qualities of leadership from the first course. It has a higher degree of continuous integration of theory, practice, and reflection throughout, made possible due to a smaller student group and the possibility for students to engage closely with a practical case throughout the course. This course supports students to (i) enhance their systems thinking and practice capabilities whilst (ii) giving shape of a future thesis topic, related to a complex and systemic "in-between" sustainability challenge in regional contexts involving multiple stakeholders. This thesis topic may be brought into the master thesis lab where the students collaborate with a researchersupervisor and identified stakeholders in a mode of TD coproduction. Previous research on C-Lab has found that three main mechanisms enabling meaningful learning for students partaking in C-Lab include: (1) "learning space," (2) "learning methodology," and (3) "learning within" (internal dimensions of learning processes), where ambitions come alive in practice (Holmén et al., 2021). For reports into student cases, see Larsson and Holmberg (2018).

The pedagogical format includes a learning space, methodology and facilitation style. The space is enacted in situations where students and stakeholders collaborate in a way that builds openness and trust via listening and dialogue balancing advocacy and inquiry (Isaacs, 1993; Schein, 1993; Sandow and Allen, 2005; Kahane, 2017). The methodology becomes enacted as a structured attempt to provide direction, movement, and guidance for learning processes. It is a key component of the C-Lab approach and builds on a sequenced yet iterative backcasting dialectic across (1) desirability-where to, why? (2) reality-what is, why? (3) transformability-what could be different, where? and (4) feasibility - what can be, how? (see Figure 1). Stakeholders are invited to the learning space with the recognition that they hold knowledge and mandate on various problematic situations that surface in contexts of

\footnotetext{
${ }^{2}$ See http://challengelab.chalmers.se for a practical overview including links to course plans and syllabus.
}

sustainability. They engage in dialogues held by students, where their perspectives on a complex issue are integrated. This is done through collaboration around an emergent challenge or question from these interactions in combination with other activities at the lab. Teachers/staff at the lab are responsible for maintaining the stakeholder network over the years, including identifying topics and themes of interest around which to invite.

In the first step, students formulate guiding principles for sustainability in combination with individual values clarification. In the second step, they analyze systems_via combining desk research, conceptual modeling, and stakeholder dialogue-in the local/regional context to identify key sustainability challenges (and root causes) from the lens of their principles. The third step moves from systems understanding to systems intervention, where students identify leverage point interventions with potential for sustainability transformation. The fourth step focuses on strategic experimentation and action with a learningorientation and care for agency. The methodological approach builds on an inviting facilitation style that seeks to create space, remove unnecessary uncertainty, maintain desirable difficulties and meet students as persons "where they are" with key attention toward their inner motivation including autonomy, competence and relatedness (Ryan and Deci, 2000). To achieve this, teachers engage as facilitators to create conditions and space, providing methodological, affective, and content support including structures for experiences exchange and reflection.

Learning outcomes commonly generated through a CLab process tend to take three broad directions, toward (1) enhanced knowledge on a complex sustainability challenge in context (outside-in), (2) enhanced sense of agency and purpose in the present (inside-out). (1) and (2) together form a basis to purposefully intervene in systems in context, which, apart from an opportunity in facilitating learning processes and contributing to sustainable systems change (3) generates capabilities for further sustainability transformation leadership work (Cf. Chikamori et al., 2019).

Students engage with sustainability challenges on different levels. These range from entrepreneurial idea development, initiating/facilitating "in-between" stakeholder collaboration, to supporting/challenging ongoing municipal or regional processes. In the case of in-between collaboration, as is most in line with the intended curriculum, two examples include (1) aligning bottomup and top-down actors in urban agriculture (2) strategizing the introduction of novel bioretention planter concepts for stormwater flow control via collaboration across administrative municipal silos and research groups.

\section{The Experienced C-Lab Curriculum}

In this section, we share experiences from activities and interactions among students to illustrate how complex sustainability challenges become framed and re-framed throughout a C-Lab curriculum, unfolding in a dialogic relationship between students, teachers as facilitators and stakeholders as co-learners and co-creators of the process.

The experiences are informed by seven years of educational research and practice in "C-Lab," where particularities into challenge framing are triggered during the C-Lab course 
1. Formulate guiding principles for a sustainable and desirable future

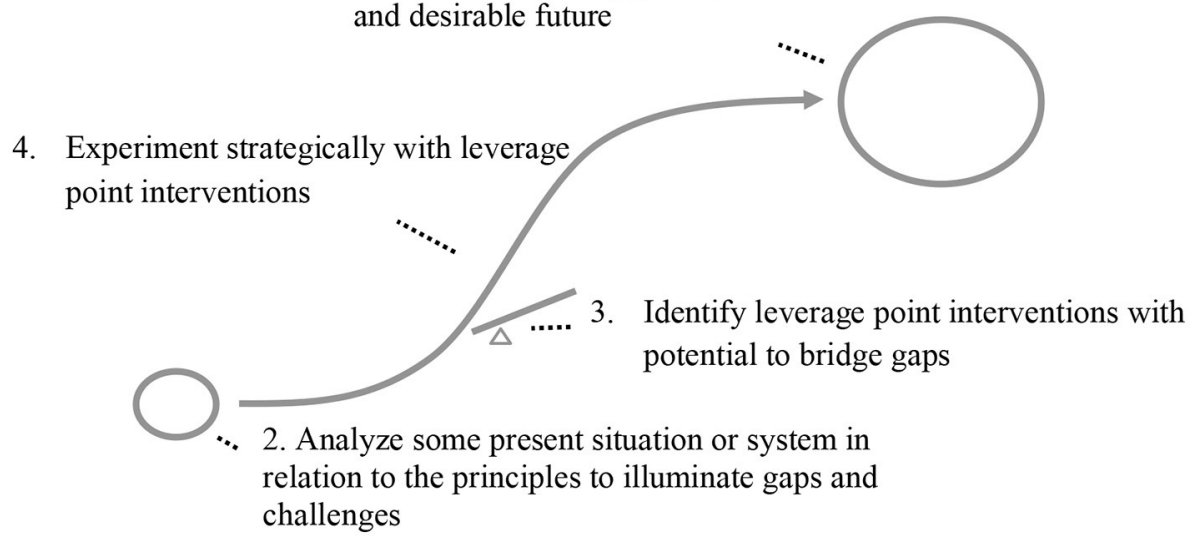

FIGURE 1 | Primary steps in a backcasting from principles methodology [adapted from Holmberg (1998) and Holmberg and Larsson (2018)].

'systems interventions for sustainability transitions. We have an embedded approach to education and research, where we investigate and learn from educational environments that we develop (Mercer, 2007). This course took place from October to December 2020 in a digital format with reduced student numbers (10) due to the COVID-19 pandemic. We share student experiences with the understanding that a C-Lab curriculum seeks to unfold in a dialogic relationship between students, teachers as facilitators and stakeholders as co-learners and cocreators of the process.

We divide the reporting of experiences related to challenge framing on two primary levels, being about (i) entering and being in a C-Lab space and (ii) procedural-practical in moving through a backcasting process in such space.

\section{Learning "Out There" and "in Here"}

A main experience of entering and being in a C-Lab space is that, in a world full of issues where one seldom feels they can contribute, there is a sense of possibility and hope. Sustainability is framed as desirability; change and transformation is framed as ongoing yet in need of influence; students are framed with capabilities and agency to meaningfully contribute to the world via the contexts in which they engage. Rather than forcing inner learning processes upon students by means of curriculum design, conditions are created for students to explore and experiment with their ways of engaging. It is voiced from students that teachers equally open up in the learning situation, where the curriculum unfolds in "real dialogue." Some students highlight that they have been acknowledged as persons in the learning space, rather than a number in the educational "machine."

Students tend to enter C-Lab with a "saving the world" attitude. This is taken seriously within the space, balanced by an awareness of possibilities and constraints to meaningfully engage. A saying held within C-Lab is to "think big, start small and act now," where students are encouraged to start somewhere (small) with larger aspirations in mind. Some students experience for the first time that they have been able to make a real difference by partaking in C-Lab. Engagement with challenges "out there" tends to spark reflection "in here," where they reflect upon and question who they are, what they do and how they contribute to sustainable change. Students often experience a shift from viewing oneself as an expert that holds knowledge and answers, toward a more listening-inquiry form of leadership.

\section{From Problem Solvers to Challenge Framers}

In C-Lab, complex sustainability challenges are not pre-given to the learning situation. Rather, students engage in a process to identify, ground, and frame such challenges. Meaningful learning experiences emerge during this process, as most participating students are educated in a problem-solving engineering tradition. Here, deductive forms of reasoning accelerate the movement toward solutions.

Despite ambitions of the C-Lab curriculum on a level of mantra and methodological design to "stay with the question"to expand everyday thinking processes, listen, and gather perspectives-there is a tendency for students to begin with preconceived solutions in open-ended attempts to formulate and frame challenges. When elaborating upon principles for sustainability and in deliberating upon various problematic situations related to sustainability in the local/regional context, students routinely express and suggest various solutions-often at a level of technology and behavior change. These tendencies appear despite our collective attempts to ground sustainability challenges as e.g., complex, systemic, political. A retrofitting or backwards tendency, where "problems" become framed to suit certain "solutions," starkly contrasts with the intentions of a backcasting-based challenge framing process.

Within C-Lab, the above tendencies are surfaced in a reflexive manner, e.g., exemplified in students stating, "we want to stop rushing for solutions, but we don't know how to!." Some of these issues are resolved by spending time in not only "doing" backcasting, but also in creating shared understanding and ownership on it at the level of intents and reasons. The group 
collectively tries, despite its difficulty, to acknowledge that such experiences appear naturally when trying to transcend everyday thinking and dealing with complexity. This encourages students to proceed with an open mind by essentially "trusting the process" and reflecting upon it as a learning experience.

Comfort levels fluctuate while moving through the various steps of the C-Lab curriculum. Even with agreement on the importance of a backcasting procedure in framing challenges, students often become uncomfortable and overwhelmed. In initial weeks of the course, some (including those who experience principles-based engagement as providing purpose and direction) perceive not only the content as fluffy or abstract, but also a delay to their engagement with "more concrete" stages. When analyzing systems in the second backcasting step, this feeling is exemplified by those who begin to feel that they are beginning to do something "real".

\section{From Analysis Paralysis to Re-negotiating Roles}

C-lab includes activities in a bid to support students to "stay with the question." During the second backcasting step students work with systems thinking tools and frameworks that are structured to understand and frame complex issues. Practically, they combine static socio-technical systems mapping with dynamic systems thinking modeling (causal loop diagramming), guided by the iceberg model metaphor, to generate systemic representations within which a sustainability challenge is present. In the process of doing so, students integrate knowledge from structured information, stakeholder perspectives and their own backgrounds. They experience substantiating a challenge as embedded within a system, making boundary and value judgements on its elements, relations, and structures. During this stage, as the complexity of the systems grows, students progressively encounter an inability to directly solve the challenge at hand in their immediate learning environment. Whilst such movements are encouraged from the intended curriculum, students express that "it feels as if we're building a mountain in front of us" when additional layers of complexity are added to the nature of the challenge. These layers may relate to the growing set of interrelated factors that are at play within a system; they may reflect the disciplinary limits ones holds in making knowledge claims about the systems one seeks to understand; they may relate to the communicative boundaries in exchanging across disciplinary boundaries and/or TD manners. During such processes, it becomes apparent that choices regarding the challenge, stakeholders and insights, leverage points, and strategies, are not self-evident; rather they are purposeful choices, informed by various forms of knowledge and experience.

After initial frustration, where expectations of a solution come into contact with a challenge that is no longer solvable in a rational manner, students begin to express relief and renegotiate what it means to be an engineer and a leader in sustainability transitions. Often, these shifts imply deliberate moves in viewing oneself as an expert to a listener, that gathers multiple perspectives on a complex challenge and sees the value in framing and re-framing challenges as a way for stakeholders to overcome issues on their own, rather than as a student try to come up with expert-solutions to complex challenges.

\section{Approaching Learning, Progress, and Contribution on Complex Issues}

The above experiences have implications for how the C-Lab group evaluates progress and judges capacity development in an open-ended learning process. Within the course, we combine both formative and summative assessments as part of an integrated evaluation strategy. Formative assessment takes place through weekly expectation and reflection sessions, organized according to a check-in, check-out structure (Holmberg, 2014). In addition, a storywall approach was adopted to jointly visualize and sense-make in the co-production of knowledge using a learning journey perspective. ${ }^{3}$ Summative assessment was facilitated through a comprehensive evaluation assessment at the end of the course, and discussed in dialogue with student representatives.

Findings show that students often experience a difficulty in making sense of their progress during this journey. When experiencing forms of uncertainty, they turn to us teachers for certain reassurances, asking questions such as "Are we moving in the right direction? Is what we have done sufficient? How do we choose where to go from here? Have we missed anything?" In C-Lab, these questions are positioned as natural and healthy when navigating a complex and uncertain world. However, a challenge for teachers is to create a setting where such contexts become conductive for learning. When a mismatch occurs, several students question whether they are moving forwards or backwards in the course and in their own learning journey. For others, they begin to conceive of their learning journey as more cyclical in nature, marked by oscillating processes of confusion and clarity. In overcoming these challenges, we try to both support students in internalizing critical questions, and provide support without closing potentially fruitful explorations. However, institutional constraints "force" both students and teachers in C-Lab to let go and move forward. This is visible in expectations from stakeholders, curriculum and students to make some kind of "progress," reflected in the importance of a final product that can be neatly packaged, presented, evaluated and shared.

\section{CONCLUDING DISCUSSION}

In this paper, we explored a TD "Challenge Lab" (C-Lab) curriculum from a perspective of challenge framing. Through provisional student experiences, framing can be viewed as embedded within an open-ended learning process, both on a level of practice and space. Experiences related to framing in C-Lab shed light on how students situate themselves and see their role within existing challenges, how they navigate limits to knowledge in complex systems, and how they self-assess their own sense of comfort and progress as they navigate curriculum. These insights

\footnotetext{
${ }^{3}$ For a process description of Storywall, see the methods and tools for co-producing knowledge from td-net: https://naturalsciences.ch/co-producingknowledge-explained/methods/td-net_toolbox/storywall.
} 
have served to further highlight the complex interplay between intention, enaction and experience in educational design. As voiced by Hume and Coll (2010), this three-pronged approach provides a nuanced basis for the evaluation of curricula. It does this by situating student and facilitator experiences within a complex learning context, where expectations and practices are dynamic. Three levels of curriculum provide a practical set of language for further investigating how curricula unfold. In further discussing this paper, we reflect upon dilemmas and opportunities that emerge during C-Lab as a teacher. We see these dilemmas as not isolated to C-Lab, and as such might resonate with learning environments where binaries such as student-teacher, classroom-real-world, and science-society are blurred. Additionally, we reflect upon the methodological limitations of this study.

\section{Teacher Reflections and Theoretical Extensions}

Firstly, we as teachers navigate C-Lab alongside students while they explore the interplay between their disciplinary predispositions as a rational engineer, and their emotional and personal responses to sustainability challenges. The assumption here is not that such tensions are immediately problematic or resolvable. Rather they are viewed as liminal states (Wallin and Aarsand, 2019), characterized by a deep questioning and reconsideration of categories such as disciplinary identity. Such liminality may be necessary for students as they approach complex challenges that are characterized by multiplicity and agency, rather than rationality. Within C-Lab, we seek to create space through continuous reflection and emotional scaffolding, where the liminal space is not focused solely on the nature of the challenge (content), but also on the nature of relations, conflicting identities, and senses of community.

Secondly, we find ourselves self-assessing our role as teacherfacilitators in closing uncertainty in a C-Lab curriculum. As elements of expansivity and transgression are incorporated into curriculum design, we continuously weigh up expressions of uncertainty that students face. In addition, we grapple with our discomfort as we encounter dilemmas where we as facilitators experience numerous uncertainties. As teachers, C-Lab requires us to continuously adapt our framing to situations in interaction with students. Sometimes we find ourselves focusing on framing issues to leave maximum agency for students to act according to their own will, sometimes we seek to frame issues to enable maximum learning for students meaning that we deliberately influence their work in certain directions. Sometimes we frame issues to maximize progress, often by connecting closely with stakeholders investing time and resources into the space who sit on complex sustainability issues on a daily basis in a position to act. These three angles on framing are not necessarily in conflict, where we have rather found it rewarding to ensure presence in all three, and for students to decide what kind of learning process, contribution, and capability development they are after.

As facilitators, we ask ourselves: What is progress here? What is enough to move forward? How do we know that we are in the right stage? Is discomfort and frustration desirable or undesirable? Do we need to adjust expectations? Dancing between uncertainty and certainty, between complexity and control, requires a continuous engagement with our collective expectations and practices from within the learning space. It involves a continuous reflection upon whether certain experiences are intended or unintended for a curriculum designed for open-endedness and emergence. It also requires those within this space to continuously trust elements of the process, whilst calling into question others. These dilemmas occur at the level of "doing teaching," and during the creation of learning space/environment.

We also experience situations where students become passive and dependent on teachers to pre-define and take control of the learning situation. This creates tension with the intended student-driven nature of the curriculum. Those issues are best handled via clarifying expectations before students eventually decide to join C-Lab. We further try to assure that those partaking have some prior motivation in contributing to sustainability transformations and a willingness to step into an open-ended learning process. A motivation of "saving the world" may lead to students wanting to take upon a too big task during their engagement, which we seek to channel by living the motto of "thinking big, starting small and acting now."

\section{Toward Further Research on Intended, Enacted and Experienced Curriculum}

In this study we structured our understanding of C-Lab according to intended, enacted, and experienced curriculum (Billett, 2006; Hume and Coll, 2010). We drew from curriculum theory, conceptualizing challenge framing curriculum as (i) intentions from students and teacher, (ii) enacted context and (iii) experienced by both students and teachers based on their own life histories.

Several methodological limitations for this study are worth mentioning. Firstly, this research concerns a particular setting at a technical University in Sweden. C-Lab itself represents an educational setting that occupies a small institutional niche within the University. Students voluntarily choose to participate in C-lab as elective courses, often in the final year of tertiary education. Methodologically, we focus our insights on a provisional set of experiences of specific situations within a curriculum related to challenge framing. These limitations impact how this study can be generalized to other contexts, regardless of curriculum design.

This study represents a first attempt to relate framing at the level of curriculum through an exploration of C-Lab. In extending the theoretical and empirical basis for challenge framing, we point toward the need to further investigate: (1) how teaching and learning to frame problems is positioned in higher education for sustainable development contexts, (2) challenge framing processes unfolding in context, where stakeholders surface, construct and negotiate frames (3) how students and stakeholders experience learning to frame challenges, and how/in which was this changes throughout a process. Grasping the intricacies of framing processes, central to learning inside and outside of educational settings, is critical for achieving 
the transformative aspirations of higher education (Sawyer, 2005). We anticipate that this future agenda, within which we situate our current paper, will contribute to existing knowledge of how complex in-between challenges are grappled with in educational environments.

\section{DATA AVAILABILITY STATEMENT}

The raw data supporting the conclusions of this article will be made available by the authors, without undue reservation.

\section{AUTHOR CONTRIBUTIONS}

All authors jointly conceived of and designed the study. GM and JHolmé jointly organized and analyzed the data, with support

\section{REFERENCES}

Ackoff, R. L. (1973). Science in the systems age: beyond IE, OR, and MS. Oper. Res. 21, 661-671. doi: 10.1287/opre.21.3.661

Andersson, C., Törnberg, A., and Törnberg, P. (2014). Societal systemscomplex or worse? Futures 63, 145-157. doi: 10.1016/j.futures.2014. 07.003

Archibald, T. (2020). What's the problem represented to be? problem definition critique as a tool for evaluative thinking. Am. J. Eval. 41, 6-19. doi: $10.1177 / 1098214018824043$

Bardwell, L. V. (1991). Problem-framing: a perspective on environmental problemsolving. Environ. Manage. 15, 603-612. doi: 10.1007/BF02589620

Barnett, R. (2004). Learning for an unknown future. High Edu. Res. Dev. 23, 247-260. doi: 10.1080/0729436042000235382

Barth, M., Godemann, J., Rieckmann, M., and Stoltenberg, U. (2007). Developing key competencies for sustainable development in higher education. Int. J. Sustain. High. Edu. 8, 416-430. doi: 10.1108/146763707108 23582

Bateson, G. (1972). Steps to an Ecology of Mind: Collected Essays in Anthropology, Psychiatry, Evolution, and Epistemology. Rockville, MD: Aronson.

Beckman, S. L., and Barry, M. (2012). Teaching students problem framing skills with a storytelling metaphor. Int. J.Eng. Edu. 28(2), 364-373. http:// exams.skule.ca/exams/\%5C'\%20.\%20 \protect|T1 \textdollarcourse $\% 20 . \% 20$ \%5C'_20161_631469077666Teaching\%20Students\%20Problem\%20Framing \%20Skills\%20with\%20a\%20Storytelling\%20Metaphor\%20\%5BBeckman $\% 202012 \% 5$ D.pdf

Benford, R. D., and Snow, D. A. (2000). Framing processes and social movements: an overview and assessment. Ann. Rev. Sociol. 26, 611-639. doi: 10.1146/annurev.soc.26.1.611

Billett, S. (2006). Constituting the workplace curriculum. J. Curriculum Stud. 38, 31-48. doi: 10.1080/00220270500153781

Bornemann, B., and Christen, M. (2020). Navigating between complexity and control in transdisciplinary problem framing: meaning making as an approach to reflexive integration. Soc. Epistemol. 34, 357-369. doi: 10.1080/02691728.2019.1706120

Boulton, J. G., Allen, P. M., and Bowman, C. (2015). Embracing Complexity: Strategic Perspectives for an Age of Turbulence. Oxford: OUP. doi: 10.1093/acprof:oso/9780199565252.001.0001

Brand, F. S., and Jax, K. (2007). Focusing the meaning(s) of resilience: resilience as a descriptive concept and a boundary object. Ecol. Soc. 12:23. doi: 10.5751/ES-02029-120123

Busch, K. C., Henderson, J. A., and Stevenson, K. T. (2019). Broadening epistemologies and methodologies in climate change education research. Environ. Edu. Res. 25, 955-971. doi: 10.1080/13504622.2018.15 14588

Chatterton, P. (2000). The cultural role of universities in the community: revisiting the University-community debate. Environ. Plan. A. Econ. Space 32, 165-181. doi: $10.1068 / \mathrm{a} 3243$ from JHolmb and TA. GM and JHolmé jointly drafted and redrafted all sections of the manuscript, with support from JHolmb and TA.

\section{ACKNOWLEDGMENTS}

We would like to thank C-Lab students and stakeholders for their curiosity, energy, and drive in learning about sustainability transitions. This research would not be possible without their continuous commitment to systems change, and their courage in moving beyond the comforts of their own disciplines. We would also like to thank the department of Communication and Learning in Science (CLS) at Chalmers University of Technology for their constructive feedback during early conceptual stages of this collaboration.

Checkland, P., and Poulter, J. (2010). "Soft systems methodology”, in Systems Approaches to Managing Change: A Practical Guide, eds M. Reynolds, and S. Holwell, 191-242. London: Springer. doi: 10.1007/978-1-84882809-4_5

Chikamori, K., Tanimura, C., and Ueno, M. (2019). Transformational model of education for sustainable development (TMESD) as a learning process of socialization. J. Crit. Realism 18, 420-436. doi: 10.1080/14767430.2019. 1667090

Chong, D., and Druckman, J. N. (2007). Framing theory. Ann. Rev. Polit. Sci. 10, 103-126. doi: 10.1146/annurev.polisci.10.072805.103054

Eden, C., and Ackermann, F. (2013). Problem structuring: on the nature of, and reaching agreement about, goals. EURO J. Decis. Process. 1, 7-28. doi: 10.1007/s40070-013-0005-6

Fam, D., Mellick Lopes, A., Ross, K., and Crosby, A. (2020). "The Transdisciplinary Living Lab Model (TDLL)," in Universities as Living Labs for Sustainable Development: Supporting the Implementation of the Sustainable Development Goals, eds W. Leal Filho, A. L. Salvia, R. W. Pretorius, L. L. Brandli, E. Manolas, F. Alves, U. Azeiteiro, J. Rogers, C. Shiel, and A. Do Paco (New York, NY: Springer International Publishing).

Holmberg, J. (1998). Backcasting: a natural step in operationalising sustainable development. Greener management international, 30-51

Holmberg, J. (2014). "4. Transformative learning and leadership for a sustainable future: challenge lab at chalmers University of technology," in Intergenerational Learning and Transformative Leadership for Sustainable Futures, eds P. B. Corcoran, B. P. Hollingshead, H. Lotz-Sisitka, A. E. J. Wals, and J. P. Weakland (Wageningen: Wageningen Academic Publishers), 91-102.

Holmberg, J., and Larsson, J. (2018). A Sustainability Lighthouse-Supporting Transition Leadership and Conversations on Desirable Futures. Sustainability, 10(11), 3842. doi: 10.3390/su10113842

Holmén, J., Adawi, T., and Holmberg, J. (2021). Student-led sustainability transformations: employing realist evaluation to open the black box of learning in a challenge Lab curriculum. Int. J. Sustain. High. Edu. 22, 1-24. doi: 10.1108/IJSHE-06-2020-0230

Hume, A., and Coll, R. (2010). Authentic student inquiry: the mismatch between the intended curriculum and the student-experienced curriculum. Res. Sci. Technol. Edu. 28, 43-62. doi: 10.1080/026351409035 13565

Irwin, T. (2015). Transition design: a proposal for a new area of design practice, study, and research. Design Cult. 7, 229-246. doi: 10.1080/17547075.2015.1051829

Isaacs, W. N. (1993). Taking flight: dialogue, collective thinking and organizational learning. Organ. Dyn. 22, 24-39. doi: 10.1016/0090-2616(93)90051-2

Ison, R. (2017). Systems Practice: How to Act. London: Springer. doi: 10.1007/978-1-4471-7351-9

Ison, R. L., Collins, K. B., and Wallis, P. J. (2015). Institutionalising social learning: towards systemic and adaptive governance. Environ. Sci. Policy 53, 105-117. doi: $10.1016 /$ j.envsci.2014.11.002 
Jackson, M. C. (2010). Reflections on the development and contribution of critical systems thinking and practice. Syst. Res. Behav. Sci. 27, 133-139. doi: $10.1002 /$ sres. 1020

Jerneck, A., and Olsson, L. (2011). Breaking out of sustainability impasses: how to apply frame analysis, reframing and transition theory to global health challenges. Environ. Innov. Societal Transit. 1, 255-271. doi: 10.1016/j.eist.2011.10.005

Kahane, A. (2017). Collaborating With the Enemy. How to Work With People You Don't Agree With or Like or Trust. San Francisco, CA: Berret-Koehler Publishers. doi: 10.1108/SL-02-2017-0013

Lang, D. J., Wiek, A., Bergmann, M., Stauffacher, M., Martens, P., Moll, P., Swilling, M., and Thomas, C. J., et al. (2012). Transdisciplinary research in sustainability science: Practice, principles, and challenges. Sustainability Science, 7(S1), 25-43. doi: 10.1007/s11625-011-0149-x

Larsson, J., and Holmberg, J. (2018). Learning while creating value for sustainability transitions: the case of challenge lab at chalmers University of technology. J. Clean. Prod. 172, 4411-4420. doi: 10.1016/j.jclepro.2017. 03.072

Latour, B. (2004). Why has critique run out of steam? from matters of fact to matters of concern. Crit. Inq. 30, 225-248. doi: 10.1086/421123

Lopes, A. M., Fam, D., and Williams, J. (2012). Designing sustainable sanitation: involving design in innovative, transdisciplinary research. Design Stud. 33, 298-317. doi: 10.1016/j.destud.2011.08.005

Lorino, P., Mourey, D., and Schmidt, G. (2017). Goffman's theory of frames and situated meaning-making in performance reviews. The case of a category management approach in the French retail sector. Account. Organ. Soc. 58, 32-49. doi: 10.1016/j.aos.2017.03.004

Lotz-Sisitka, H., Mukute, M., Chikunda, C., Baloi, A., and Pesanayi, T. (2017). Transgressing the norm: transformative agency in community-based learning for sustainability in southern African contexts. Int. Rev. Edu. 63, 897-914. doi: 10.1007/s11159-017-9689-3

Lotz-Sisitka, H., Wals, A., Kronlid, D., and McGarry, D. (2015). Transformative, transgressive social learning: rethinking higher education pedagogy in times of systemic global dysfunction. Curr. Opin. Environ. Sustain. 16, 73-80. doi: 10.1016/j.cosust.2015.07.018

Lund, C. (2014). Of what is this a case?: Analytical movements in qualitative social science research. Hum. Organ. 73, 224-234. doi: 10.17730/humo.73.3.e35q482014x03314

Meadows, D. H. (1997). Places to intervene in a system. Whole Earth 91, 78-84.

Meadows, D. H. (2008). Thinking in Systems: A Primer. Hartford, CT: Chelsea Green Publishing.

Mercer, J. (2007). The challenges of insider research in educational institutions: wielding a double-edged sword and resolving delicate dilemmas. Oxford Rev. Edu. 33, 1-17. doi: 10.1080/03054980601094651

Mezirow, J. (1997). Transformative learning: theory to practice. New Dir. Adult Contin. Edu. 1997, 5-12. doi: 10.1002/ace.7401

Midgley, G. (2000). Systemic Intervention. Berlin: Springer. doi: 10.1007/978-1-4615-4201-8

Moon, J. (2001). Reflection in Higher Education Learning PDP Working Paper 4. New York, NY: Learning and Teaching Support Network.

Moore, J. (2005). Is higher education ready for transformative learning?: a question explored in the study of sustainability. J. Transform. Edu. 3, 76-91. doi: $10.1177 / 1541344604270862$

Moser, S. C. (2021). If it is life we want: a prayer for the future (of the) University. Front. Sustain. 2:662657. doi: 10.3389/frsus.2021.662657

Ness, B. (2020). "Approaches for framing sustainability challenges: experiences from swedish sustainability science education," in Framing in Sustainability Science, eds T. Mino, and S. Kudo (Singapore: Springer), 35-53. doi: 10.1007/978-981-13-9061-6_3

O'Brien, K. (2013). Global environmental change III: closing the gap between knowledge and action. Prog. Hum. Geogr. 37, 587-596. doi: 10.1177/0309132512469589

Pohl, C., Pearce, B., Mader, M., Senn, L., and Krütli, P. (2020). Integrating systems and design thinking in transdisciplinary case studies. GAIA Ecol. Perspect. Sci. Soc. 29, 258-266. doi: 10.14512/gaia.29.4.11

Rittel, H. W., and Webber, M. M. (1973). Planning problems are wicked. Polity 4:e169. doi: 10.1007/BF01405730
Robinson, J. (2008). Being undisciplined: transgressions and intersections in academia and beyond. Futures 40, 70-86. doi: 10.1016/j.futures.2007. 06.007

Ross, K., and Mitchell, C. (2018). "Transforming transdisciplinarity: an expansion of strong transdisciplinarity and its centrality in enabling effective collaboration," in Transdisciplinary Theory, Practice and Education, eds D. Fam, L. Neuhauser, and P. Gibbs (Basel: Springer International Publishing). doi: 10.1007/978-3-319-93743-4_4

Ryan, R. M., and Deci, E. L. (2000). Self-determination theory and the facilitation of intrinsic motivation, social development, and well-being. Am. Psychol. 55:68. doi: 10.1037/0003-066X.55.1.68

Saldaña, J. (2021). The Coding Manual for Qualitative Researchers. Thousand Oaks, CA: Sage.

Sandow, D., and Allen, A. M. (2005). The nature of social collaboration: how work really gets done. Reflect. SoL J. 6, 2-3. Retreived/accessed from https://vetu.pw/ digital237.pdf

Sawyer, R. K. (2005). The Cambridge Handbook of the Learning Sciences. Cambridge: Cambridge University Press. doi: 10.1017/CBO97805118 16833

Schein, E. H. (1993). On dialogue, culture, and organizational learning. Organ. Dyn. 22, 40-51. doi: 10.1016/0090-2616(93)90052-3

Schön, D. A. (2008). The Reflective Practitioner: How Professionals Think In Action. New York, NY: Basic Books.

Sipos, Y., Battisti, B. and Grimm, K. (2008), "Achieving transformative sustainability learning: engaging head, hands and heart”. Int. J. Sustain. High. Edu., 9(1), 68-86. doi: 10.1108/146763708108 42193

Star, S. L., and Griesemer, J. R. (1989). Institutional ecology,translations' and boundary objects: amateurs and professionals in Berkeley's museum of vertebrate zoology, 1907-1939. Soc. Stud. Sci. 19, 387-420. doi: 10.1177/030631289019003001

Svihla, V., and Reeve, R. (2016). Facilitating problem framing in projectbased learning. Interdiscipl. J. Probl. Based Learn. 10(2), 1-18. doi: 10.7771/1541-5015.1603

Thomas, I. (2009). Critical thinking, transformative learning, sustainable education, and problem-based learning in universities. J. Transform. Edu. 7, 245-264. doi: 10.1177/1541344610385753

Tilbury, D. (2012). Higher education for sustainability: A global overview of commitment and progress. In GUNI Higher Education in the World 4: Higher Education's Commitment to Sustainability from Understanding to Action; Granados, J., Ed.; Pallgrave Macmillan: Glasgow, Scotland, UK, 2012; $18-28$.

Tilbury, D. (2016). "Student engagement and leadership in higher education for sustainability," in Routledge Handbook of Higher Education for Sustainable Development, eds M. Barth, G. Michelsen, M. Rieckmann, and I. Thomas (Oxford: Routledge), 273-286.

Trencher, G., Yarime, M., McCormick, K. B., Doll, C. N. H., and Kraines, S. B. (2014). Beyond the third mission: exploring the emerging University function of co-creation for sustainability. Sci. Public Policy 41, 151-179. doi: $10.1093 / \mathrm{scipol} / \mathrm{sct} 044$

UNESCO (2014). Shaping the Future We Want: UN Decade of Education for Sustainable Development (2005-2014): Final Report; UNESCO: Paris, France..

van der Horst, D., and Staddon, S. (2018). Types of learning identified in reflective energy diaries of post-graduate students. Energy Efficiency 11, 1783-1795. doi: 10.1007/s12053-017-9588-2

Vilsmaier, U., and Lang, D. J. (2015). Making a difference by marking the difference: Constituting in-between spaces for sustainability learning. Curr. Opin. Environ. Sustain. 16, 51-55. doi: 10.1016/j.cosust.2015. 07.019

Wallin, P., and Aarsand, L. (2019). Challenging spaces: liminal positions and knowledge relations in dynamic research partnerships. Int. J. Stud. Partners 3 69-83. doi: 10.15173/ijsap.v3i1.3739

Wallin, P., and Adawi, T. (2018). The reflective diary as a method for the formative assessment of self-regulated learning. Eur. J. Eng. Edu. 43, 507-521. doi: 10.1080/03043797.2017.1290585 
Waters, J. L. (2017). Education unbound? enlivening debates with a mobilities perspective on learning. Prog. Hum. Geogr. 41, 279-298. doi: $10.1177 / 0309132516637908$

West, S., Kerkhoff, L., and Wagenaar, H. (2019). Linking Knowledge and Action for Sustainability: Towards a Practice-based Approach. Policy Stud., 40(5), 534-556. doi: 10.1080/01442872.2019.1618810

Wiek, A., Withycombe, L., and Redman, C. L. (2011). Key competencies in sustainability: a reference framework for academic program development. Sustain. Sci. 6, 203-218. doi: 10.1007/s11625-011-0132-6

Will, M., and Rydén, L. (2015). "Trans-disciplinarity in sustainability science and education," in Integrative Approaches to Sustainable Development at University Level (Basel: Springer International Publishing), 687-705, 687-707. doi: 10.1007/978-3-319-10690-8_47

Winter, J., Cotton, D., Hopkinson, P., and Grant, V. (2015). The University as a site for transformation around sustainability. Int. J.Innov. Sustain. Dev. 9, 303-320. doi: 10.1504/IJISD.2015.071857

Yin, R. K. (2011). Qualitative Research From Start to Finish. New York, NY: Guilford Press.
Conflict of Interest: The authors declare that the research was conducted in the absence of any commercial or financial relationships that could be construed as a potential conflict of interest.

Publisher's Note: All claims expressed in this article are solely those of the authors and do not necessarily represent those of their affiliated organizations, or those of the publisher, the editors and the reviewers. Any product that may be evaluated in this article, or claim that may be made by its manufacturer, is not guaranteed or endorsed by the publisher.

Copyright (c) 2021 McCrory, Holmén, Holmberg and Adawi. This is an open-access article distributed under the terms of the Creative Commons Attribution License (CC $B Y)$. The use, distribution or reproduction in other forums is permitted, provided the original author(s) and the copyright owner(s) are credited and that the original publication in this journal is cited, in accordance with accepted academic practice. No use, distribution or reproduction is permitted which does not comply with these terms. 